\section{俩 Heighten Science \\ P U B L I C I T I O N S Corporation ISSN \\ 2576-9537}

\title{
Intestinal obstruction complicated by large Morgagni hernia
}

\author{
Martín Arnau B*, Medrano Caviedes R, Rofin Serra S, \\ Caballero Mestres F and Trias Folch M \\ General and Digestive Surgery, Unit of Emergency, Santa Creu i Sant Pau Hospital, Barcelona, \\ Spain
}

\section{*Address for Correspondence: Martín Arnau $B$, General and Digestive Surgery, Unit of Emergency, Santa Creu i Sant Pau Hospital, Barcelona, Spain, Email: amartinar@santpau.cat \\ Submitted: 06 March 2017 \\ Approved: 24 March 2017 \\ Published: 27 March 2017}

Copyright: @ 2017 Martín Arnau B, et al. This is an open access article distributed under the Creative Commons Attribution License which permits unrestricted use, distribution, and reproduction in any medium, provided the original work is properly cited.

Keywords: Morgagni hernia; Intestinal obstruction; Damage control

\section{ABSTRACT}

Morgagni hernia represents $2-4 \%$ of congenital diaphragmatic hernias. Only one-third of them are symptomatic, due to the hernia of abdominal viscera in the thoracic cavity, causing respiratory and digestive problems, some of them serious ones, such as intestinal obstruction. Acute presentation with incarceration of the contents is rare; there are only 7 cases described in the literature.

We are presenting a case of diaphragmatic hernia that began with obstruction of the colon and secondary ischemia, requiring emergency surgery in two phases: first surgery to control the damage, with an open right hemicolectomy, and then later surgery to repair the hernia and perform bowel transit reconstruction, with proper postoperative evolution and no evidence of relapse.

The treatment of Morgagni diaphragmatic hernia is surgical. Also in asymptomatic cases, due to the risk of incarceration, the most appropriate way to enter is abdominally, whether by way of laparotomy or laparoscopy, for the reduction of the contents of the hernia sac, the repair of the defect, as well as the performing of associated techniques on herniated viscera, as occurred in our case.

A complicated congenital hernia is an infrequent pathology, and there is little experience in handling it. Acute presentation requires a combined treatment of the abdominal symptoms and repair of the hernia defect. The carrying over of surgical techniques for damage control into non-traumatic surgery in the face of serious hemodynamic instability is a widespread, accepted practice with the benefits of reducing mortality in critical patients and at times allowing the avoidance of ostomies.

\section{INTRODUCTION}

There are four types of congenital diaphragmatic hernia: hiatal hernia, paraoesophageal hernia, Bochdalek hernia, and Morgagni-Larrey hernia. The latter represents $2-4 \%$, and is predominantly on the right side [1-3]. It is usually diagnosed incidentally while performing medical imaging for something else. In symptomatic cases (which is only one-third of them), it is due to the hernia of the abdominal viscera inside the thoracic cavity, causing respiratory problems (difficulty breathing, thoracic pain) or digestive ones (painful swallowing, reflux, abdominal pain, intestinal occlusion) $[1,3,4]$. However, acute presentation with incarceration is rare; only 7 cases are described in the literature $[1,2,5,6]$.

Its treatment is surgical, and the classic approach is a laparotomy, and more rarely, thoracotomy, but in recent years, several procedures using laparoscopy or thoracoscopy [7-9], have been described. There is little experience because of the infrequency of the pathology.

We are presenting a case of diaphragmatic hernia that began with obstruction of the colon and secondary ischemia, requiring emergency surgery in two phases: first surgery to control the damage, and then later surgery to repair the hernia defect, which evolved properly. 


\section{CASE PRESENTATION (CASE REPORT)}

The case was a man, aged 52, who came in for diffuse abdominal pain with four days of evolution, without clinical signs of obstruction or other symptoms. Physical examination showed a distended, drum-like abdomen with signs of peritoneal irritation. The thoracic x-ray showed hydro-aerial levels in the right hemithorax that erased the cardiac silhouette, with elevation of the ipsilateral hemidiaphragm. The patient showed clinical worsening with hypotension, tachycardia, respiratory distress, and elevation of reactants in the acute phase, metabolic acidosis, and acute renal insufficiency.

An emergency abdominal CT scan was performed, showing a large anterior diaphragmatic hernia that contained right colon with thickening of the wall and free liquid suggesting intestinal suffering, without pneumoperitoneum (Figure 1). Emergency surgery was performed, and the herniated right colon could be seen at the ipsilateral hemithorax, with signs of ischemia and necrosis, through a hernia orifice of about 10x15 cm (Figure 2). Given the critical state of the patient, it was decided to perform damage control surgery with right hemicolectomy without primary anastomosis, leaving the abdomen open.

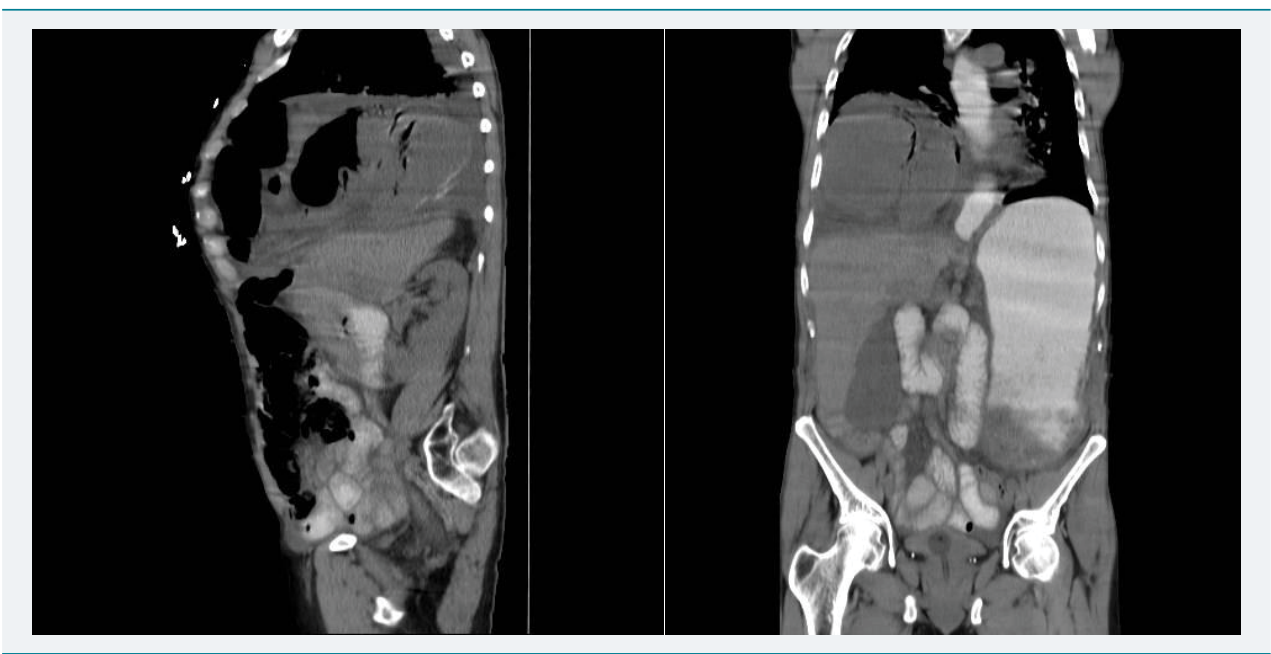

Figure 1: Right chest fluid levels in previous hemidiaphragm defect Gastric dilatation.

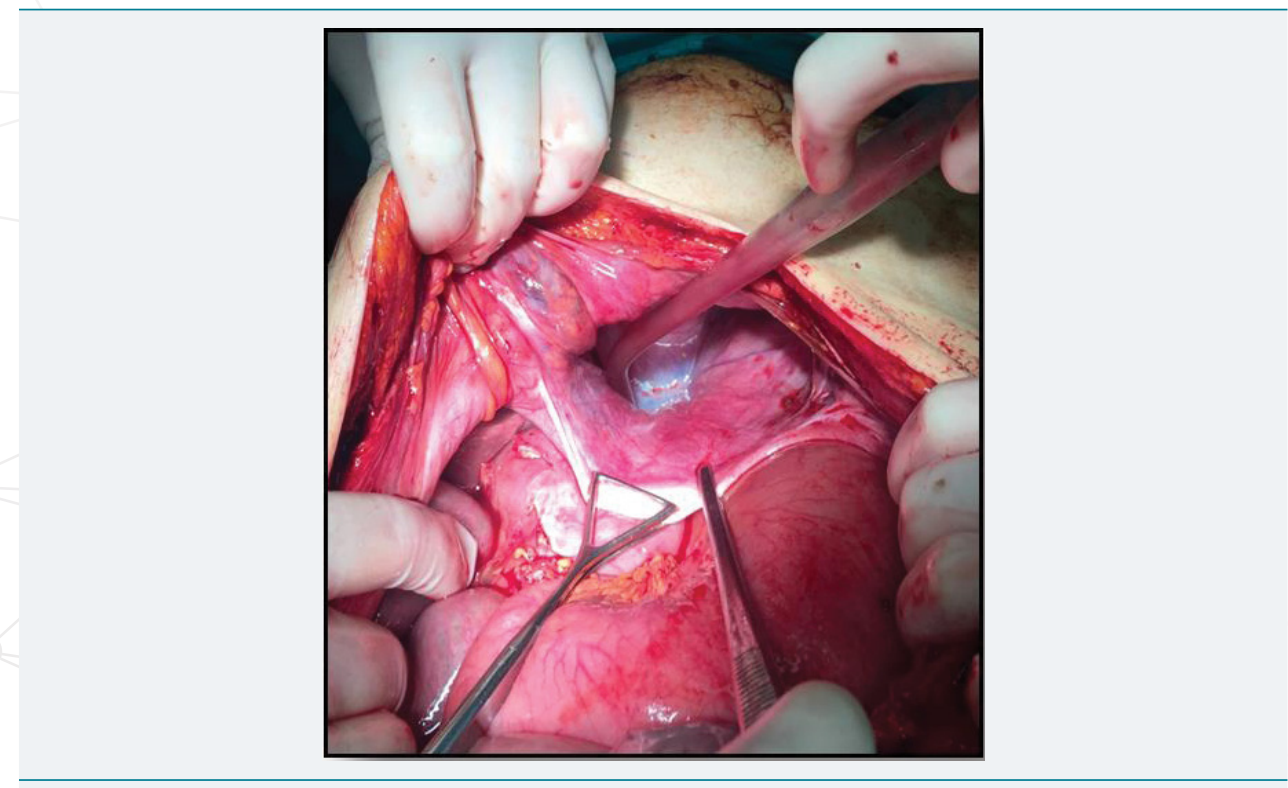

Figure 2: Great hernia defect with sack prolapsed right chest. 
The patient was moved to an intensive care unit with improvement of the shock immediately after the operation. At 72 hours, another operation was performed, with ileocolic anastomosis, resection of the hernia sac, repair of the defect using simple raffia (Figures 3-5) and closing the abdominal wall. Two weeks later, he was released by the surgical team. In the control x-ray a right pneumothorax associated with pleural effusion without clinical repercussion was seen, so it was handled in a conservative manner, evolving well, and he was released from medical leave one month after surgery. At one year follow up, he remains without recurrence.

\section{DISCUSSION}

The Morgagni hernia is a diaphragmatic hernia which, like hiatal hernia, almost always has a peritoneal sac, unlike other diaphragmatic hernias such as the Bochdalek or those caused by traumatic breakage of the diaphragm. Its transverse diameter is

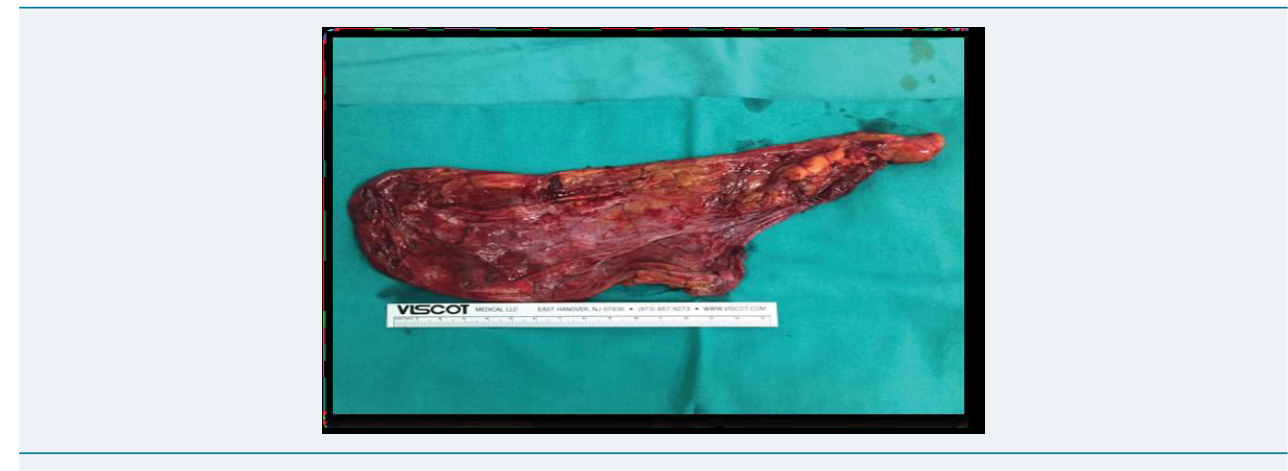

Figure 3: Hernial sac resection

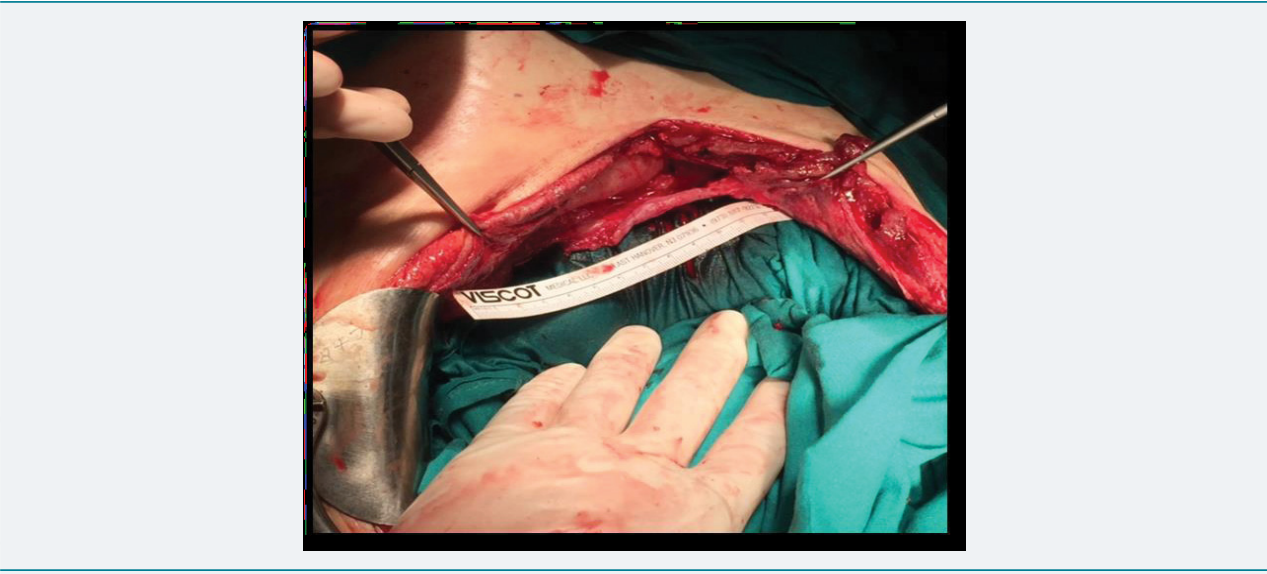

Figure 4: Hernia defect after resection of the sac about $10 \times 15 \mathrm{~cm}$.

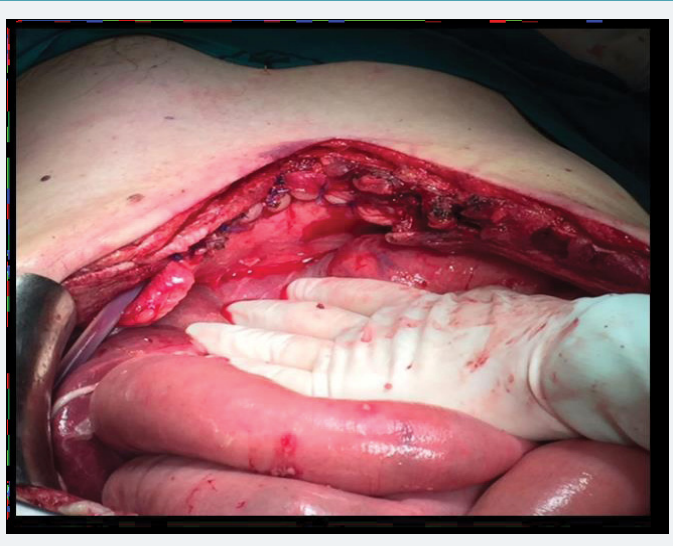

Figure 5: Rafia single defect without tension, with continuous absorbable suture. 
usually greater than anterior-posterior diameter [1]. They contain, from greater to lesser frequency: Omentum (31\%), transverse colon $(29 \%)$, stomach $(15 \%)$, small intestine $(11 \%)$, liver $(4 \%)$, caecum, or appendix $[1,3]$.

Although the Morgagni hernia is considered a congenital defect, diagnosed in small children, it is usually detected in an adult, either accidentally in medical imaging requested for another reason, or in most cases, symptomatically $[2,3,5,6]$. This would indicate that additional mechanisms acquired by an adult age are necessary to increase intra-abdominal pressure (obesity, pregnancy, ascites, chronic constipation, paralytic ileus, injury, etc.) to cause the visceral hernia that leads to symptomatic presentation $[1,3,4]$.

This radiological find suggests differential diagnosis with things such as: Lyposarcoma, neurofibroma, pericardial cyst, tuberculoma, lung cancer, pneumonia, lymphoma, teratoma, empyema, hydatid cyst, or other diaphragmatic hernias.

The treatment of the Morgagni-Larrey diaphragmatic hernia is surgical. Some authors recommend it both in symptomatic and asymptomatic [1,3] cases, due to the risk of incarceration. The most indicated approach, both in laparotomy and in laparoscopic surgery, is abdominal, as this allows the reduction of the contents of the hernia sac and repair of the defect, as well as the performance of diverse techniques of intestinal resection for the ischemia of abdominal viscera. It also allows good access in hernias with bilateral presentation $[2,3,5,6,8,10]$.

As in our case, we used the abdominal approach to achieve a correct reduction of the hernia sac and the simultaneous intestinal resection.

We want to emphasize the applicability of damage control surgery in patients who requiring emergency surgery. Two phases: first surgery to control the damage, removing septic focus produced by intestinal necrosis, without primary anastomosis and leaving the abdomen open. After a second phase with resuscitation an intensive care unit, allowing a second look at 48-72 hours, to repair the hernia and perform bowel transit reconstruction in correct hemodynamic conditions $[11,12]$.

The carrying over of surgical techniques for damage control into non-traumatic surgery in the face of serious hemodynamic instability is a widespread, accepted practice with the benefits of reducing mortality in critical patients and at times allowing the avoidance of ostomies [11-13].

In elective surgery, after the reduction of the herniated abdominal viscera, performing resection of the sac or not is an aspect that is still controversial. There are authors, such as Contini et al., who describe [11] that in cases of the preservation of the sac, small residual thoracic cysts form, for which reason in these cases, they recommend leaving drainage in the thoracic cavity to minimise the phenomenon. On the other hand, some complications described after exeresis are pneumomediastinum or pneumothorax $[1,5]$, like our patient presented.

With respect to the repair of the diaphragmatic defect through simple closure by primary suture or with prosthetic mesh, some authors such as Thoman et al. indicate the use of [1] prosthesis in large defects $(20-30 \mathrm{~cm})$, to bring about a repair without tension. Someone authors prefer not to excise the hernial sac and favor suturing the defects before mesh reinforcement. Regarding the type of mesh used, composite, expanded polytetrafluoroethylene (ePTFE), or polypropylene are the available options [8]. Other authors recommend its use in all cases except for newborns $[1,3,7,11,12]$. We used simple raffia without tension, and one year after the surgery, there has been no relapse.

Both abdominal and thoracic laparoscopic approaches have also been described, 
although less frequently than the open one. As advantages, they offer a better view of the surgical field, easy reduction of the hernia contents, the possibility of simple closing or the use of mesh, and the surgery is less aggressive, decreasing postoperative pain and the length of the hospital stay $[2,3,7,8,9,11]$. The post-operative complications described in the bibliography are: Atelectasis with serious respiratory insufficiency, pneumothorax, pneumomediastinum, subcutaneous emphysema, CO2 embolism (in laparoscopic surgery techniques) and reappearance of the hernia, among others. Regarding this laparoscopic approach, morbidity and mortality rates are low $[1,3,4,9]$.

\section{CONCLUSION}

Complicated congenital hernia is an infrequent pathology, and there is little experience in handling it. Acute presentation requires a combined treatment of the obstruction and repair of the hernia defect. According to our experience, abdominal laparotomy is quick and safe, allowing proper examination, with repair using simple raffia, with satisfactory recovery afterwards, without any signs of relapse. Comparison should be made with more cases to determine the effectiveness of this technique.

\section{REFERENCES}

1. Horton JD, Hofmann LJ, Hetz SP. Presentation and management of Morgagni hernias in adults: a review of 298 cases. Surgical Endoscopy. 2008; 22: 1413-1420. Ref.: https://goo.gl/TpVjmB

2. McBride R, Brown T, Dasari B, Scoffield J. Large bowel obstruction due to anterior diaphragmatic hernia (of Morgagni) on the right side. BMJ Case Rep. 2012. Ref.: https://goo.gl/d1W4YS

3. Shah RS, Sharma PC, Bhandarkar DS. Laparoscopic repair of Morgagni's hernia: an innovative approach. Journal of Indian Association of Pediatric Surgeons. 2015; 20: 68-71. Ref.: https://goo.gl/SP6ZRL

4. Abraham V, Myla Y, Verghese S, Chandran BS. Morgagni-Larrey Hernia-a Review of 20 Cases. Indian J Surg. 2012; 74: 391-395. Ref.: https://goo.gl/VrHBmD

5. Pallati PK, Puri V, Mittal SK. Gastric outlet obstruction secondary to Morgagni hernia: a case report. The World Journal of Hernia and Abdominal Wall Surgery. 2008; 12: 209-212. Ref.: https://goo.gl/Hka5XB

6. Rattay T, Ubhi S. Morgagni hernia-an uncommon cause of gastric outlet obstruction. BMJ Case Rep. 2011. Ref.: https://goo.gl/MEVaaP

7. Kashiwagi $H$, Kumagai K, Nozue M, Terada Y. Morgagni hernia treated by reduced port surgery. Int $J$ Surg Case Rep. 2014; 5: 1222-1224. Ref.: https://goo.gl/VltZUL

8. Palanivelu C, Rangarajan M, Rajapandian S, Amar V, Parthasarathi R. Laparoscopic repair of adult diaphragmatic hernias and eventration with primary sutured closure and prosthetic reinforcement: a retrospective study. Surg Endosc. 2009; 23: 978-985. Ref.: https://goo.gl/1ALW1L

9. Park A, Doyle C. Laparoscopic Morgagni Hernia Repair: How I Do It. J Gastrointest Surg. 2014; 18: 1858-1862. Ref.: https://goo.gl/D73640

10. Facy $O$, Cheynel $N$, Ortega Deballon $P$, Rat $P$. Tratamiento quirúrgico de las Hernias diafragmáticas raras. Enciclopedia Medicoquirúrgica. 2012; 40-247. Ref.: https://goo.gl/effmnp

11. Weber DG, Bendinelli C, Balogh ZJ. Damage control surgery for abdominal emergencies. Br J Surg. 2014; 101: 109-118. Ref.: https://goo.gl/Kh1SVa

12. Beckman M, Paul J, Neideen T, Weigelt JA. Role of the Open Abdomen in Critically III Patients. Crit Care Clin. 2016; 32: 255-264. Ref.: https://goo.gl/sRf9vG

13. Khan A, Hsee L, Mathur S, Civil I. Damage-control laparotomy in nontrauma patients: review of indications and outcomes. J Trauma Acute Care Surg. 2013; 75: 365-368. Ref.: https://goo.gl/fq3eqo 